\title{
Systematic review of Lamendin's dental age estimation method
}

\begin{abstract}
- Juliana Ribeiro Lopes Department of Social Dentistry, School of Dentistry, University of São Paulo, São Paulo, SP, Brazil • Mário Marques Fernandes Department of Social Dentistry, School of Dentistry, University of São Paulo, São Paulo, SP, Brazil • Edgar Michel-Crosato Department of Social Dentistry, School of Dentistry, University of São Paulo, São Paulo, SP, Brazil • Rodolfo Francisco Haltenhoff Melani Department of Social Dentistry, School of Dentistry, University of São Paulo, São Paulo, SP, Brazil • Rogério Nogueira Oliveira Department of Social Dentistry, School of Dentistry, University of São Paulo, São Paulo, SP, Brazil
\end{abstract}

ABSTRACT | Objective: to determine the effectiveness of Lamendin's dental age estimation, by conducting a systematic review. Methods: for the meta-analysis, we searched for studies with the aim of showing the effectiveness of the method by comparing the chronological and estimated ages of the sample. Three databases were consulted (MEDLINE, LILACS, and EMBASE). We excluded studies with historical samples and those that changed the technique, analyzed other aspects of the method without presenting results on effectiveness, and that presented the sample in a single group with individuals under 25 years of age. The quality evidence scale QUADAS was used with some modifications. The final sample consisted of eight studies. Results: our results showed that the identified studies were methodologically careless and that the method was ineffective in older people, but produced good estimates for adults in other age-ranges. There are discrepancies in the literature regarding the age at which the method works best. Relevance: Studies on Lamendin's technique should have a stricter methodological approach and the technique should be tested before being used in a given population to verify the age at which the results are more accurate.

DESCRIPTORS Forensic Dentistry; Age Determination by Teeth; Evidence-Based Dentistry; Meta-Analysis.

RESUMO | Revisão sistemática do método Lamedin para estimativa da idade pelos dentes • Objetivo: verificar a eficácia do método de estimativa de idade de Lamendin por meio de uma revisão sistemática. Métodos: para a metanálise foram pesquisados estudos que tinham como objetivo mostrar a eficácia do método comparando as idades cronológica e estimada da amostra. Foram consultadas as bases de dados MEDLINE, LILACS e EMBASE. Excluímos os artigos com amostra histórica, os que modificaram a técnica, os que analisaram outros aspectos do método sem retratar sua eficácia e os que apresentaram a amostra em grupo único com indivíduos de menos de 25 anos de idade. Em seguida, a escala de qualidade de evidência QUADAS foi utilizada com modificações. A amostra final foi constituída de oito estudos. Resultados: os resultados mostraram que os estudos identificados descuidam de alguns aspectos metodológicos e que o método é ineficaz em idosos, mas que produz boas estimativas nos outros adultos. Existem discordâncias na literatura quanto à faixa etária em que o método funciona melhor. Relevância: os estudos que utilizam essa técnica necessitam de mais rigor metodológico, e a técnica deve ser testada antes de ser usada numa determinada população para que seja possível constatar em qual faixa etária os resultados são mais precisos..

DESCRITORES | Odontologia legal; Determinação da idade pelos dentes; Odontologia Baseada em Evidências; Metanálise.

CORRESPONDING AUTHOR | • Rogério Nogueira de Oliveira Department of Social Dentistry, School of Dentistry University of São Paulo • Av. Prof. Lineu Prestes, 2227 Cidade Universitária, São Paulo, SP, Brazil • 05508-000 E-mail: rogerion@usp.br

- Received Jan 27,2015 • Accepted Mar 5, 2015

• Dol http://dx.doi.org/10.11606/issn.2357-8041.clrd.2016.89865 


\section{INTRODUCTION}

\section{Posing the question}

Age determination by teeth is an important part of Forensic Dentistry and Anthropology, since this method provides valuable assistance in cases of identification. For many years and up to now, the scientific community has produced a large number of researches on this topic. Several of them ${ }^{1-3}$ are based on the developmental stages of teeth, which makes them suitable for estimating the age of children and adolescents. For adults, methods are often based on degenerative modifications, such as attrition, periodontosis, transparency of the root, secondary dentin, cementum apposition, and root resorption.

Since Gustafson ${ }^{4}$ first published his work on age determination by degenerative changes in teeth, several authors $5^{-8}$ have developed other methods based on the characteristics he described, including Lamendin et al. ${ }^{9}$ The technique was developed to be simple, and its purpose was to estimate the age of adults at the time of death. The method consists of analyzing only two dental variables (periodontosis and transparency) and applying the numbers to a given formula, and it is a good option for use in forensic cases.

In view of the doubt about the real efficacy of the methods, the precepts of Evidence-Based Dentistry were considered for evaluating the quality of the results shown by the studies of estimating age in adults.

However, it is a challenge to show its application to a specialty that is not part of the clinical routine in dentistry, such as Forensic Dentistry. Thus, in spite of this type of review integrating existent information in an efficient format and providing data for rational decision-making, such studies are rarely observed within Forensic Dentistry.

Thus, considering the importance to society of estimating age, and that a simple and efficient method for use in adults would facilitate the process of identification in Brazil, we chose to evaluate the efficiency of Lamendin's technique.

\section{MATERIAL AND METHODS}

\section{Finding the studies}

We collected diagnostic studies of Lamendin's method for estimating age, alone or in comparison with another method, provided that they presented the results of each method individually.

The data of the results of interest include the comparison of dental age obtained as a result of the application of the method with the previously known chronological age.

The identification was performed by searching for articles in the MEDLINE, LILACS, and EMBASE databases, using the terms "Lamendin", "age estimation", "dental age estimation", "adult dental aging technique", "age determination", and "age determination by teeth".

At first, we carried out the so-called selection stage, in which the articles identified by the inclusion criteria were once again evaluated, but this time in accordance with the exclusion criteria of the systematic review. In this stage, we observed whether the studies published the results of the application of Lamendin's method, comparing chronological and estimated ages; whether there had been any change in the original technique; and whether individuals under 25 years old had been included in the sample.

To reach the final sample, the selected articles went through the process of classifying the quality of evidence, with the help of the QUADAS scale ${ }^{10}$ for diagnostic studies of accuracy, adapted to the studied method. Two examiners performed this stage, so that the studies were only included if there was agreement between the two examiners.

\section{CRITICAL EVALUATION}

Since the efficiency of the age estimation methods were analyzed in a different way from that of conventional diagnostic tests, the data collection table created for this study deviated from the tables more 
commonly observed in systematic reviews of diagnostic test studies. In this case, the most important issue was to verify to what extent the estimated age approximated the chronological age, which were the factors that could influence the process of estimation, and whether the methodology applied was reliable.

For this purpose, the following data were recorded:

- Population: The country of origin of the sample, or whether it belonged to some collection or presented some particularity.

- Burial: Whether this occurred and how long ago.

- Exposure: Whether the sample was exposed to any substance or element, and what it was.

- Dental Condition: The state in which the studied teeth were found.

- Size of the Tooth/Skull sample (T/S): The number of teeth and skulls of which the sample was composed.

- Standard Reference: Source of obtaining the chronological age.

- Doubt in the standard reference: Whether the age obtained as standard reference left room for doubt.

- Blind: Whether the specific study had been conducted in this manner or not.

- Intra-examiner: Whether the intra-examiner variance was verified.

- Inter-examiner: Whether the inter-examiner variance was verified.

- Groups: Into which types of groups the sample was divided.

- Best result (group): Which groups presented the best results of the study in question.

- Mean value of differences: What was the mean value of differences calculated for the groups of age-ranges.

- $P$ (estimated x chronological age): Whether $P$ was presented for the comparisons between estimated age and chronological age.
- Specific formula: Whether the study developed a specific formula for the studied population.

- Best result (formula): When a new formula was developed, was there any record of whether it presented better results than the original formula of Lamendin's method.

- Statistical proof (formula): Whether there was statistical comparison between the results of the original and specific formula.

After gathering and tabulation of the data, the information obtained was descriptively analyzed and examined in the form of a meta-analysis as well. Statistical treatment was performed with the software program BioEstat $\AA$ 5.0, with 95\% confidence interval

The study was properly approved by the Research Ethics Committee of the School of Dentistry of University of São Paulo, with protocol number 76/11 and CAAE 0086.0.017.000-11.

\section{RESULTS}

\section{Data gathering}

The process resulted in 13 identified articles which met the inclusion criteria, all being products of searches in the online databases. The chosen articles were the following:

1. Baccino E, Ubelaker DH, Hayek LAC, Zerilli A. Evaluation of seven methods of estimating age at death from mature human skeletal remains. J Forensic Sci.1999 Sept;44(5):931-6.

2. Foti B, Adalian P, Signoli M, Ardagna Y, Dutour O, Leonetti G. Limits of the Lamendin method in age determination. Forensic Sci Int. 2001 Nov 1;122(2-3):101-6. doi:10.1016/S0379-0738(01)o0472-8.

3. González-Colmenares G, Botella-López MC, Moreno-Rueda G, Fernández-Cardenete JR. Age estimation by a dental method: A comparison of Lamendin's and Prince \& Ubelaker's 
technique. J Forensic Sci. 2007 Sept;52(5):11566o. doi: 10.1111/j.1556-4029.2007.00508.x.

4. Kimmerle EH, Prince DA, Berg GE. Interobserver variation in methodologies involving the pubic symphysis, sternal ribs, and teeth. J Forensic Sci. 2008 May;53(3):5946oo. doi: 10.1111/j.1556-4029.2008.00715.x.

5. Lamendin H, Baccino E, Humbert JF, Tavernier JC, Nossintchouk RM, Zerilli A. A simple technique for age estimation in adult corpses: The two criteria dental method. J Forensic Sci. 1992 Sept;37(5):1373-9.

6. Martrille L, Ubelaker DH, Cattaneo C, Seguret F, Tremblay M, Baccino E. Comparison of four skeletal methods for the estimation of age at death on white and black adults. J Forensic Sci. 2007 Mar;52(2):3027. doi: 10.1111/j.1556-4029.2006.00367.x.

7. Meinl A, Huber CD, Tangl S, Gruber GM, Teschler-Nicola M, Watzek G. Comparison of the validity of three dental methods for the estimation of age at death. Forensic Sci Int. 2008 Jul;178(23):96-105. doi: 10.1016/j.forsciint.2008.02.008.

8. Prince DA, Konigsberg LW. New formulae for estimating age-at-death in the Balkans utilizing Lamendin's dental technique and Bayesian analysis. J Forensic Sci. 2008 May;53(3):57887. doi: 10.1111/j.1556-4029.2008.00713.x.

9. Prince DA, Ubelaker DH. Application of Lamendin's adult dental aging technique to a diverse skeletal sample. J Forensic Sci. 2002 Jan;47(1):107-16. 10. Sarajlić N, Cihlarz Z, Klonowski EE, Selak I, Brkić H, Topić B. Two-criteria dental aging method applied to a Bosnian population: comparison of formulae for each tooth group versus one formula for all teeth. Bosn J Basic Med Sci. 2006 Aug;6(3):78-83. 11. Schmitt A, Saliba-Serre B, Tremblay M, Martrille L. An evaluation of statistical methods for the determination of age of death using dental root translucency and periodontosis. J Forensic Sci. 2010 May;55(3):5906. doi: 10.1111/j.1556-4029.2010.01341.x. 12. Soomer H, Ranta H, Lincoln MJ, Penttilä A, Leibur E. Reliability and validity of eight dental age estimation methods for adults. J Forensic Sci. 2003 Jan;48(1):149-52. 13. Ubelaker DH, Parra RC. Application of three dental methods of adult age estimation from intact single rooted teeth to a Peruvian sample. J Forensic Sci. 2008 May;53(3):60811. doi: 10.1111/j.1556-4029.2008.00699.x.

For the effect of practicality, these articles will be referred to by their corresponding numbers in the abovementioned description of the selection process.

\section{Analysis and presentation of data}

After identification of the studies, we conducted the selection stage. At this point, the studies that fitted into the exclusion criteria of the systematic review were discarded. Thus, those that changed the original technique in an unacceptable manner or failed to present statistical results regarding the efficacy of the method were excluded. An example of acceptable change is the use of a pachymeter to replace the millimetric ruler, and the dry point compass to measure the variables. Therefore, article 3 was excluded because it measured the root transparency on the distal surface, in contrast to the original method, while articles 4 and 11 were excluded because they only compared the variance of the examiners when making measurements and only performed statistical tests to confirm whether there was a relationship between the variables and age, respectively, both without worrying about reflecting the efficacy of the method.

Since the used formula does not allow age estimation of those under 25 years old, the studies with samples that included individuals of up to 24 
years were only accepted when they presented independent results for the age groups. Thus, it was possible to evaluate only the results of the groups over 25 years old, with the intention of avoiding this bias. In articles 7, 8, and 13, the results were presented in age groups, and therefore, in spite of including individuals under 25 years old in their samples, they were not excluded. Whereas in studies 1 and 12 the samples were analyzed as a single group, and were thus discarded. Afterwards, the texts of the selected studies $-2,5,6,7,8,9,10$, and 13 - were fully evaluated in accordance with the level of scientific evidence. At this stage, the QUADAS evaluation table was used because it has been specifically developed for diagnostic accuracy tests. ${ }^{10}$
Originally, the QUADAS evaluation table consisted of 14 questions that could be answered with "Yes", "No", and "Uncertain" (Table 1). However, as an age estimation method, it does not constitute a typical diagnostic test, and some adaptations to the evaluation table were necessary, so that it could be suited to the technique. Ages at death varied from 30 to 81 years, with mean of 49.08 years.

Items $3,4,6,7,9,11,12$, and 13 were excluded, mainly because they dealt with the standard reference that, because it was chronological age, did not allow interpretations and description of the method, in addition to not undergoing alterations with time, with these characteristics being questioned in the items excluded.

Table 1 | The QUADAS tool.

\begin{tabular}{|c|c|c|c|}
\hline Item & Yes & $\begin{array}{l}\text { ( ) No } \\
\text { ( ) }\end{array}$ & Unclear \\
\hline 1. Was the spectrum of patients representative of the patients who will receive the test in practice? & $($ ) & $($ ) & () \\
\hline 2. Were selection criteria clearly described? & $($ ) & $($ ) & $($ ) \\
\hline 3. Is the reference standard likely to correctly classify the target condition? & $($ ) & $($ ) & $($ ) \\
\hline $\begin{array}{l}\text { 4. Is the time period between reference standard and index test short enough to be reasonably sure that the } \\
\text { target condition did not change between the two tests? }\end{array}$ & $($ ) & $($ ) & $($ ) \\
\hline $\begin{array}{l}\text { 5. Did the whole sample or a random selection of the sample receive verification using a reference standard of } \\
\text { diagnosis? }\end{array}$ & $($ ) & $($ ) & $($ ) \\
\hline 6. Did patients receive the same reference standard regardless of the index test result? & $($ ) & $($ ) & $($ ) \\
\hline $\begin{array}{l}\text { 7. Was the reference standard independent of the index test (i.e. the index test did not form part of the reference } \\
\text { standard)? }\end{array}$ & $($ ) & $($ ) & $($ ) \\
\hline 8. Was the execution of the index test described in sufficient detail to permit replication of the test? & $($ ) & () & () \\
\hline 9. Was the execution of the reference standard described in sufficient detail to permit its replication? & $($ ) & ( ) & $($ ) \\
\hline 10. Were the index test results interpreted without knowledge of the results of the reference standard? & $($ ) & ( ) & ( ) \\
\hline 11. Were the reference standard results interpreted without knowledge of the results of the index test? & () & ( ) & $($ ) \\
\hline $\begin{array}{l}\text { 12. Were the same clinical data available when test results were interpreted as would be available when the } \\
\text { test is used in practice? }\end{array}$ & () & () & () \\
\hline 13. Were uninterpretable/ intermediate test results reported? & $($ ) & ( ) & () \\
\hline 14. Were withdrawals from the study explained? & $($ ) & $($ ) & $($ ) \\
\hline
\end{tabular}

Source: Whiting et al. ${ }^{17}$ 
At the end, there were remaining items in numbers 1, 2, 5, 8, 10, and 14. The articles that were approved in the selection stage were then evaluated by two examiners in this exclusion stage. The items were responded in the following manner:

\section{Was the spectrum of patients representative of} the patients who will undergo the test in practice?

The answer to this question is "Yes" when the sample had demographic and clinical characteristics similar to those of the group that will undergo the test in practice. Therefore, balance between the number of individuals of both sexes and age groups was considered. In forensic cases, it is common for there to be more male than female individuals, but, when the discrepancy was very large, the sample could be considered representative if the authors mentioned the choice of cases to balance them, for example, producing the mean of similar ages.

If the sample was made up of part of a collection, then it was necessary for the authors to explain the choice of included cases to which the answer would be "Yes".

2. Were the selection criteria clearly described?

To answer "Yes" to this question, it is necessary for the inclusion and exclusion criteria to be clearly explained in the study. It was considered sufficient for the studies to have stated the origin of the individuals, and the type and conditions of the teeth used in the sample.

5. Was the entire sample or a random part of it verified in accordance with the standard reference?
The intention in this item is to know whether the results obtained by the test under study were verified, in all or in part of the sample, by the standard reference. In the case of this study, the answer was "Yes" if the estimated ages were compared with the individuals' chronological ages.

8. Was the performance of the test under study described in sufficient detail to allow replication of the test?

If the explanation of the technique of the test under study left no doubts about how it was performed, the answer given was "Yes".

10. Were the results of the test under study interpreted without there being any knowledge of the standard reference?

To exclude the possibility of influencing the results of the test under study, it is necessary for it to be performed without one knowing the result of the standard reference. Therefore, if the researchers did not know the chronological age of the individuals when they applied the test under study, the answer given was "Yes".

14. Were the desistances/exclusions from the study explained?

When studies are conducted with patients, it is possible that some of them quit or simply do not continue with the necessary follow-up; when this occurs, these desistances must be explained by the authors. In the case of the studies in question, it is possible that after application of the test under study, some characteristics of the individuals may be perceived, which prevents them from remaining in the sample. If these exclusions were explained, or if there were no 
reasons to suspect that there were exclusions, the item was marked as "Yes". ${ }^{10}$

As a parameter for inclusion, it was considered that at least $50 \%$ of "Yes" answers would be adequate. Since the eight questions excluded could also be answered as "Yes", with over 50\% positive, the studies would have a minimum of 11 affirmative responses. In cases in which the evaluation differed between the two examiners, the most negative result was considered, so that there would be no doubt about the quality of the study in question. The results were grouped in Table 2.
As may be observed in the chart, articles 6 and 10 had four "Yes" answers, that is, the lowest number of positive results. Articles 2, 5, 9, and 13 had five "Yes" answers, while numbers 7 and 8 had all positive responses. Thus, all the articles fulfilled the requisite and were accepted for the systematic review.

The data of each of the studies was collected, as shown in Table 3.

It may be observed that many data referring to the conditions of the sample, such as burial, exposure to substances, or status of dental units are not specified by the authors. ${ }^{9,11-15}$

Table 2 | Quality of evidence of articles with modified QUADAS.

\begin{tabular}{|c|c|c|c|c|c|c|c|c|}
\hline Item & 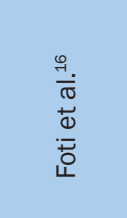 & 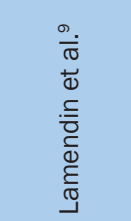 & 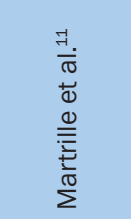 & 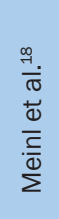 & 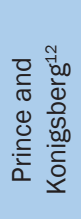 & 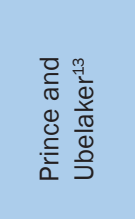 & 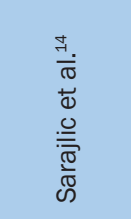 & 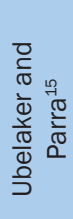 \\
\hline $\begin{array}{l}\text { 1. Was the spectrum of patients representative } \\
\text { of the patients who will undergo the test in } \\
\text { practice? }\end{array}$ & Yes & Yes & Uncertain & Yes & Yes & Yes & No & Yes \\
\hline 2. Were the selection criteria clearly described? & Yes & Yes & Yes & Yes & Yes & Yes & Yes & Yes \\
\hline $\begin{array}{l}\text { 5. Was the entire sample or a random part of } \\
\text { it verified in accordance with the standard } \\
\text { reference? }\end{array}$ & Yes & Yes & Yes & Yes & Yes & Yes & Yes & Yes \\
\hline $\begin{array}{l}\text { 8. Was the performance of the test under study } \\
\text { described in sufficient detail to allow replication } \\
\text { of the test? }\end{array}$ & Yes & Yes & No & Yes & Yes & Yes & Yes & No \\
\hline $\begin{array}{l}\text { 10. Were the results of the test under study } \\
\text { interpreted without there being any knowledge } \\
\text { of the standard reference? }\end{array}$ & Uncertain & Uncertain & Yes & Yes & Yes & Uncertain & Uncertain & Yes \\
\hline $\begin{array}{l}\text { 14. Were the desistances/exclusions from the } \\
\text { study explained? }\end{array}$ & Yes & Yes & Yes & Yes & Yes & Yes & Yes & Yes \\
\hline
\end{tabular}

It was not always explicit how the chronological age was obtained, mainly in cases in which the sample formed part of a collection. It is known that age is identified due to the register of the collection, but it is not known how the information for the register was first collected.

We also noted that most studies ${ }^{9,11,13,15,16}$ did not make it clear whether they were blind studies or not, but at least half of them provided intra- and inter-examiner statistics, while one was imprecise regarding this.

All the studies divided the sample into age groups and proved that the method presents divergent results in different age-ranges. Four studies $^{12,14-16}$ observed that the groups with more precise age estimations were those of up to 50 years of age, differently from the remainder of the researches. 


\begin{tabular}{|c|c|c|c|c|c|c|c|c|c|c|c|c|}
\hline 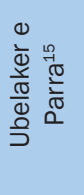 & $\frac{2}{0}$ & 㞱 & 㞱 & 㞱 & 웜 & 岂 & 㞱 & $\stackrel{\infty}{\nu}$ & 우 & $\stackrel{\circ}{z}$ & 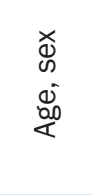 & $\begin{array}{l}\dot{m}^{0} \\
\dot{m} \\
\dot{m} \\
\frac{0}{\pi}\end{array}$ \\
\hline 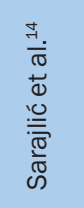 & 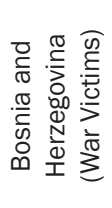 & $\begin{array}{l}\frac{\infty}{\pi} \\
0 \\
0 \\
0 \\
0 \\
0 \\
0 \\
0\end{array}$ & 岂 & 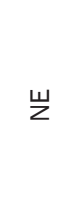 & 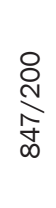 & 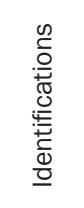 & zo & z & z & 을 & 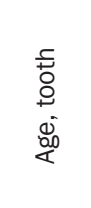 & 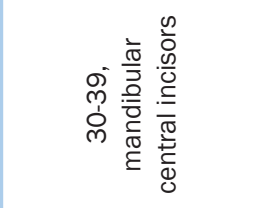 \\
\hline 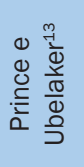 & 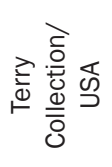 & 岂 & 岂 & 岁 & $\begin{array}{l}\stackrel{\circ}{0} \\
\stackrel{0}{\circ} \\
\stackrel{ᄋ}{+}\end{array}$ & 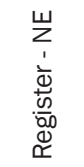 & 岂 & $\stackrel{o}{z}$ & $\stackrel{\mathscr{\infty}}{\nu}$ & $\stackrel{\mathscr{D}}{\nu}$ & 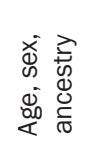 & 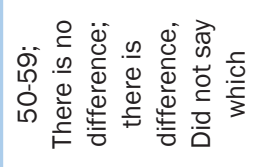 \\
\hline 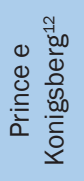 & $\begin{array}{l}\stackrel{0}{0} \\
0 \\
0 \\
\stackrel{0}{2}\end{array}$ & 岂 & 岁 & 岁 & 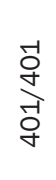 & 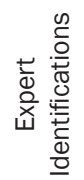 & $\overrightarrow{0}$ & $\stackrel{\infty}{\nu}$ & $\stackrel{\infty}{ల}$ & $\stackrel{\mathscr{d}}{\nu}$ & 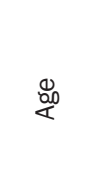 & $\begin{array}{l}\text { g } \\
\text { o } \\
+\end{array}$ \\
\hline 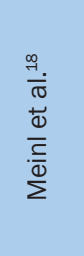 & 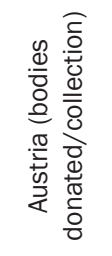 & 岂 & 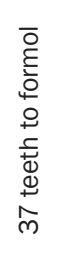 & 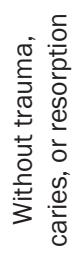 & 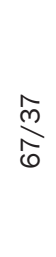 & 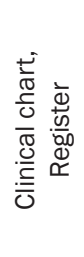 & $\begin{array}{l}\text { 岁 } \\
\text { o }\end{array}$ & $\stackrel{\infty}{\nu}$ & $\stackrel{\infty}{\nu}$ & $\stackrel{\mathscr{D}}{\nu}$ & 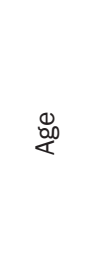 & $\begin{array}{l}\text { ণ } \\
\text { ̊े }\end{array}$ \\
\hline 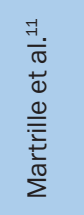 & 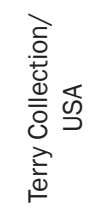 & 岂 & 岁 & 岁 & 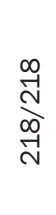 & 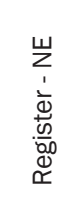 & 岂 & $\stackrel{0}{z}$ & $\stackrel{0}{z}$ & 을 & 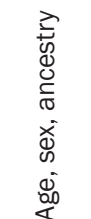 & 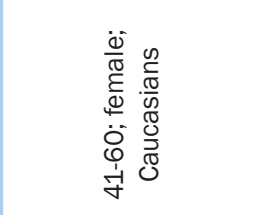 \\
\hline 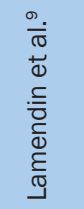 & 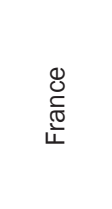 & 岂 & 岂 & 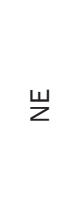 & 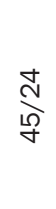 & 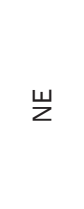 & 岂 & 㞱 & 㞱 & 㞱 & 离 & 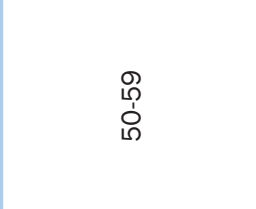 \\
\hline 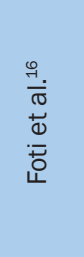 & 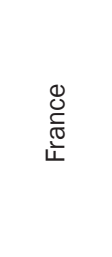 & 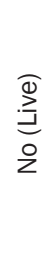 & $\begin{array}{l}\frac{0}{0} \\
\frac{0}{0} \\
\frac{0}{0} \\
\frac{0}{0} \\
\frac{0}{0} \\
\frac{0}{2}\end{array}$ & 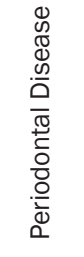 & $\frac{\sqrt{1}}{\sqrt{1}}$ & 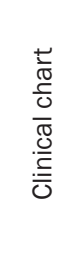 & 우 & $\stackrel{o}{z}$ & $\stackrel{\infty}{\rightleftharpoons}$ & $\stackrel{\mathscr{D}}{\nu}$ & 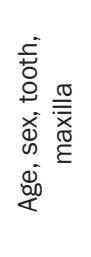 & 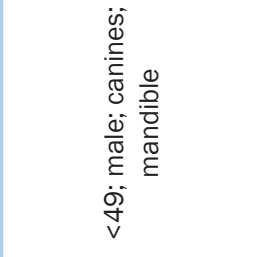 \\
\hline & $\begin{array}{l}\frac{1}{\circ} \\
\frac{0}{\overline{0}} \\
\frac{0}{0} \\
\frac{0}{0}\end{array}$ & 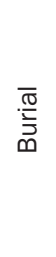 & 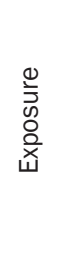 & 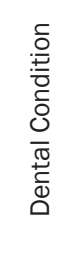 & $\begin{array}{l}\infty \\
\stackrel{\infty}{1} \\
0 \\
\frac{N}{\infty} \\
0 \\
0 \\
\frac{0}{E} \\
0 \\
\infty\end{array}$ & 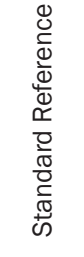 & 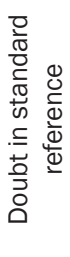 & 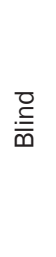 & 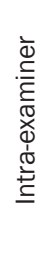 & 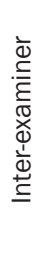 & $\begin{array}{l}00 \\
\frac{0}{3} \\
\frac{0}{0}\end{array}$ & 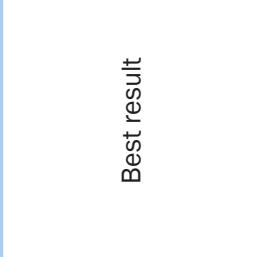 \\
\hline
\end{tabular}




\begin{tabular}{|c|c|c|c|c|c|}
\hline 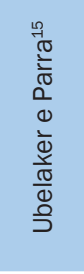 & 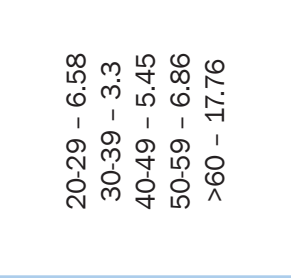 & 2o & $\stackrel{\mathscr{D}}{\nu}$ & 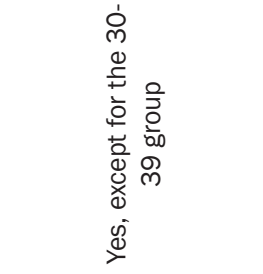 & z \\
\hline 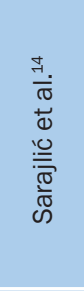 & 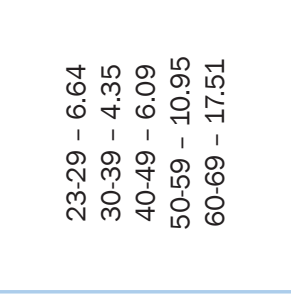 & z & 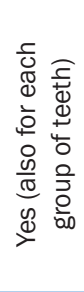 & 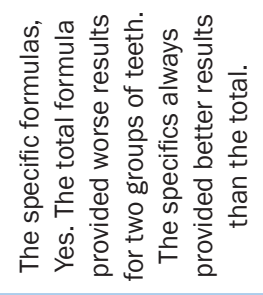 & $\stackrel{\mathscr{D}}{\nu}$ \\
\hline 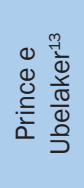 & 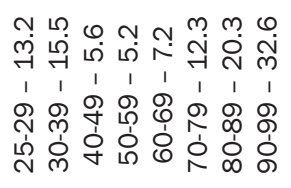 & 2o & $\stackrel{\mathscr{D}}{\rightleftharpoons}$ & $\stackrel{\mathscr{0}}{\nu}$ & $\stackrel{\mathscr{0}}{\nu}$ \\
\hline 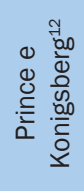 & 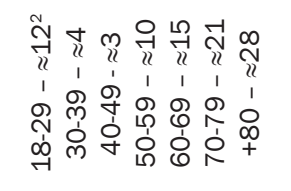 & 2 & 2 & $\begin{array}{l}\frac{0}{0} \\
\frac{0}{0} \\
\frac{.0}{0} \\
\frac{0}{0} \\
\frac{0}{2}\end{array}$ & $\begin{array}{l}\frac{0}{0} \\
\frac{0}{0} \\
\frac{0}{0} \\
\frac{0}{0} \\
\text { 茂 }\end{array}$ \\
\hline 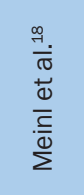 & 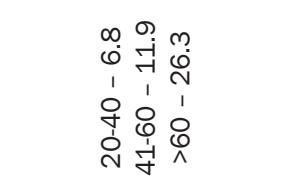 & z & z & $\begin{array}{l}\frac{0}{0} \\
\frac{0}{\overline{0}} \\
\frac{\overline{0}}{0} \\
\frac{0}{0} \\
\frac{0}{2}\end{array}$ & $\begin{array}{l}\frac{0}{0} \\
\frac{0}{0} \\
\frac{0}{0} \\
\frac{0}{0} \\
\frac{0}{2}\end{array}$ \\
\hline 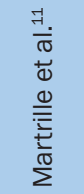 & 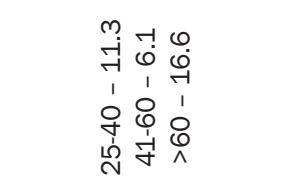 & $\stackrel{o}{z}$ & $\begin{array}{l}\frac{0}{0} \\
\frac{0}{00} \\
\frac{0}{0} \\
\frac{0}{00} \\
\frac{0}{2} \\
\frac{0}{2}\end{array}$ & $\begin{array}{l}\frac{0}{0} \\
\frac{0}{\overline{0}} \\
\frac{0}{0} \\
\frac{0}{0} \\
\frac{0}{2}\end{array}$ & $\begin{array}{l}\frac{0}{0} \\
\frac{0}{0} \\
\frac{0}{0} \\
\frac{0}{0} \\
\frac{0}{2}\end{array}$ \\
\hline 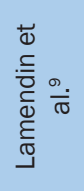 & 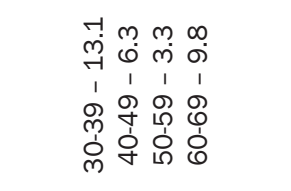 & z & $\begin{array}{l}\frac{0}{0} \\
\frac{0}{0} \\
\frac{0}{0} \\
\frac{0}{0} \\
\frac{0}{2}\end{array}$ & $\begin{array}{l}\frac{0}{0} \\
\frac{0}{0} \\
\frac{.0}{0} \\
\frac{0}{0} \\
\frac{0}{2} \\
\frac{0}{z}\end{array}$ & $\begin{array}{l}\frac{0}{0} \\
\frac{0}{0} \\
\frac{0}{0} \\
\frac{0}{0} \\
\stackrel{0}{2}\end{array}$ \\
\hline 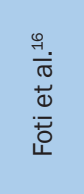 & 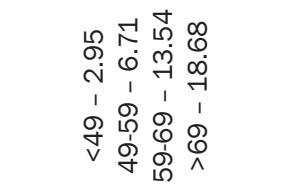 & $\stackrel{\infty}{\nu}$ & $\begin{array}{l}\frac{0}{0} \\
\frac{0}{00} \\
\frac{.0}{0} \\
\frac{0}{0} \\
\frac{0}{2} \\
2\end{array}$ & $\begin{array}{l}\frac{0}{0} \\
\frac{0}{0} \\
\frac{.0}{\overline{0}} \\
\frac{0}{0} \\
\stackrel{0}{0} \\
2\end{array}$ & $\begin{array}{l}\frac{0}{0} \\
\frac{0}{0} \\
\frac{.0}{0} \\
\frac{0}{10} \\
\stackrel{0}{0} \\
z\end{array}$ \\
\hline & 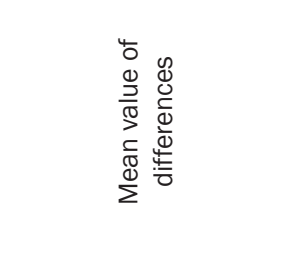 & 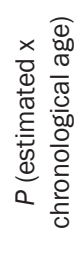 & 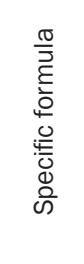 & 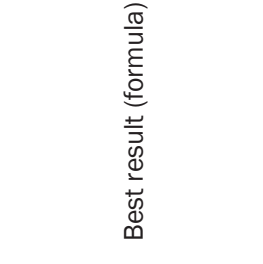 & 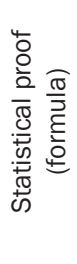 \\
\hline
\end{tabular}


In addition, some authors divided their samples according to sex, ancestry, type of tooth, and maxilla, but the results of these groups were also not constant. Studies showed better results for males ${ }^{15,16}$, females ${ }^{11}$, and no differences observed between the sexes ${ }^{13}$.

Of the two articles that compared the types of teeth, on $\mathrm{e}^{16}$ observed more precise results in canines, while the other ${ }^{14}$ found greater agreement between mandibular central incisors.

On the other hand, Prince and Ubelaker ${ }^{13}$ observed differences between Caucasians and Afro-descendants, but did not go into the subject in-depth, and did not specify whether one group would be more precise than the other, in disagreement with Martrille et al., ${ }^{11}$ who observed better results in Caucasians. Foti et al. ${ }^{16}$ also found greater precision in the mandible than in the maxilla.

The means of the differences in the age groups ranged from 2.95 to 32.6. It was possible to observe that the very high values occur only in older individuals. The best mean values of each study ranged from 2.95 to 6.8; it is worth pointing out that this latter value belongs to a group that included individuals under 25 years old. However, only Foti et al. ${ }^{16}$ calculated the $P$ to verify whether the differences found would be statistically significant.

Lastly, the data regarding the development of a specific formula for the researched population showed that, of the five articles that could develop one, three ${ }^{13-15}$ did so. Moreover, it was found that in general, these formulas provided better results than the original formula, but Ubelaker and Parra ${ }^{15}$ did not use statistics to show that the new formula produced significantly better results.

The meta-analysis show by age groups 30-39, 40-49, 50-59, and 60-69, used by the studies ${ }^{14-16}$ that the real and estimated ages have the following y differences: 4.30 years ( $\mathrm{p}<0,01), 5.27$ years ( $p<0,01), 9.07$ years $(\mathrm{p}<0,01)$, and 16.62 years ( $\mathrm{p}<\mathrm{o}, 01)$, respectively.
The group of up to 29 years old was excluded because it comprised individuals under 25 years old.

\section{DISCUSSION}

\section{Enhancing and updating the review}

The studies could have had some more methodological rigor regarding the balance of the sample and its particular characteristics. However, the methodologies used were sufficient to provide the results with quality evidence and verify that Lamendin's method is efficient. Nevertheless, due to the different results presented by the diverse samples, we suggest that the method should be tested in the population in which one intends to apply it, to verify in which age range it produces the best results, and thus, diminish the possibility of error. A constant factor in the researches is the observation of overestimations in young individuals and underestimations in older subjects. In addition, the technique loses its efficacy when applied to individuals of over 60 years of age.

\section{REFERENCES}

1. Moorrees CF, Fanning EA, Hunt EE Jr. Age variation of formation stages for ten permanent teeth. J Dent Res. 1963 Nov;42(6):1490-502. doi: 10.1177/00220345630420062701.

2. Demirjian A, Goldstein H, Tanner JM. A new system of dental age assessment. Hum Biol. 1973 May [cited 2016 Feb 23];45(2):211-27. Available from: http://www.jstor.org/stable/41459864.

3. Cameriere R, Ferrante L, Cingolani M. Age estimation in children by measurement of open apices in teeth. Int $\mathrm{J}$ Legal Med. 2006 Jan;120(1):49-53. doi: 10.1007/soo414-005-0047-9.

4. Gustafson G. Age determination on teeth. J Am Dent Assoc. 1950 Jul;41(1):45-54.

5. Johnson CC. Transparent dentine in age estimation. Oral Surg Oral Med Oral Pathol. 1968 Jun;25(6):834-8.

6. Bang G, Ramm E. Determination of age in humans from root dentin transparency. Acta Odontol Scand. 1970;28(1):3-35. doi: 10.3109/00016357009033130. 
7. Kvaal SI, Kolltveit KM, Thomsen IO, Solheim T. Age estimation of adults from dental radiographs. Forensic Sci Int. 1995;74(3):175-85. doi: 10.1016/0379-0738(95)O1760-G.

8. Cameriere R, Ferrante L, Cingolani M. Variations in pulp/ tooth area ratio as an indicator of age: a preliminary study. J Forensic Sci. 2004;49(2):317-9. doi: 10.1520/JFS2003259.

9. Lamendin H, Baccino E, Humbert JF, Tavernier JC, Nossintchouk RM, Zerilli A. A simple technique for age estimation in adult corpses: The two criteria dental method. J Forensic Sci. 1992 Sept;37(5):1373-9. doi: 10.1520/JFS13327J.

10. Whiting PF, Weswood ME, Rutjes AW, Reitsma JB, Bossuyt PN, Kleijnen J. Evaluation of QUADAS, a tool for the quality assessment of diagnostic accuracy studies. BMC Med Res Methodol. 2006 Mar;6:9. doi: 10.1186/1471-2288-6-9.

11. Martrille L, Ubelaker DH, Cattaneo C, Seguret F, Tremblay M, Baccino E. Comparison of four skeletal methods for the estimation of age at death on white and black adults. J Forensic Sci. 2007 Mar;52(2):302-7. doi: 10.1111/j. 1556-4029.2006.00367.x.

12. Prince DA, Konigsberg LW. New formulae for estimating age-at-death in the Balkans utilizing Lamendin's dental technique and Bayesian analysis. J Forensic Sci. 2008 May;53(3):578-87. doi: 10.1111/j.1556-4029.2008.00713.x.

13. Prince DA, Ubelaker DH. Application of Lamendin's adult dental aging technique to a diverse skeletal sample. J Forensic Sci. 2002 Jan;47(1):107-16. doi: 10.1520/JFS15209J.

14. Sarajlić N, Cihlarz Z, Klonowski EE, Selak I, Brkić H, Topić B. Two-criteria dental aging method applied to a Bosnian population: comparison of formulae for each tooth group versus one formula for all teeth. Bosn J Basic Med Sci. 2006 Aug;6(3):78-83.

15. Ubelaker DH, Parra RC. Application of three dental methods of adult age estimation from intact single rooted teeth to a
Peruvian sample. J Forensic Sci. 2008 May;53(3):608-11. doi: 10.1111/j.1556-4029.2008.00699.x.

16. Foti B, Adalian P, Signoli M, Ardagna Y, Dutour O, Leonetti G. Limits of the Lamendin method in age determination. Forensic Sci Int. 2001 Nov 1;122(2-3):101-6. doi: 10.1016/ So379-0738(01)00472-8.

17. Whiting P, Rutjes AWS, Reitsma JB, Bossuyt PMM, Kleijnen J. The development of QUADAS: a tool for the quality assessment of studies of diagnostic accuracy included in systematic reviews. BMC Med Res Methodol. 2003 Nov;3:25. doi: 10.1186/1471-2288-3-25.

18. Meinl A, Huber CD, Tangl S, Gruber GM, Teschler-Nicola M, Watzek G. Comparison of the validity of three dental methods for the estimation of age at death. Forensic Sci Int. 2008 Jul;178(2-3):96-105. doi: 10.1016/j.forsciint.2008.02.008.

19. Kimmerle EH, Jantz RL, Konigsberg LW, Baraybar JP. Skeletal estimation and identification in American and East European populations. J Forensic Sci. 2008 May;53(3):524-32. doi: 10.1111/j.1556-4029.2008.00708.x.

20. Soomer H, Ranta H, Lincoln MJ, Penttilä A, Leibur E. Reliability and validity of eight dental age estimation methods for adults. J Forensic Sci. 2003;48(1):149-52.

21. Ubelaker DH, Parra RC. Application of three dental methods of adult age estimation from intact single rooted teeth to a Peruvian sample. J Forensic Sci. 2008 [cited 2014 Sept 10];53(3):608-11. Available from: http://onlinelibrary.wiley. com/doi/10.1111/j.1556-4029.2008.00699.x/full

22. Whiting PF, Weswood ME, Rutjes AW, Reitsma JB, Bossuyt PN, Kleijnen J. Evaluation of QUADAS, a tool for the quality assessment of diagnostic accuracy studies. BMC Med Res Methodol 2006 [cited 2014 Sept 10];6:9. Available from: http:// www.biomedcentral.com/1471-2288/6/9 